\title{
Occurrence, Distribution, and Characteristics of Boscalid-Resistant Corynespora cassiicola in China
}

Fadi Zhu, Yanxia Shi, Xuewen Xie, Ali Chai, and Baoju Li, ${ }^{\dagger}$ Institute of Vegetables and Flowers, Chinese Academy of Agricultural Sciences, Beijing, 100081, China

\begin{abstract}
Corynespora blight, caused by Corynespora cassiicola (Berk. \& M.A. Curtis) C.T. Wei, has become an important disease affecting cucumber in China. Its management mainly depends on fungicides; however, no research has been conducted to assess the sensitivity of $C$. cassiicola in China to boscalid, a succinate dehydrogenase inhibitor (SDHI). To facilitate boscalid resistance monitoring, baseline sensitivity was established. The $\mathrm{EC}_{50}$ value (i.e., the concentration that results in $50 \%$ mycelial growth inhibition) frequency distribution was unimodal with a right-hand tail; with the means $0.95 \pm 0.51 \mu \mathrm{g} / \mathrm{ml}$ and the range 0.03 to $2.85 \mu \mathrm{g} / \mathrm{ml}$. We then assessed the sensitivity of $C$. cassiicola to boscalid using discriminatory doses and $\mathrm{EC}_{50}$ values. In total, $27.8 \%$

of the 798 isolates were resistant, distributed in five provinces and two municipalities. Thirty-seven isolates with different resistance levels to boscalid were also evaluated for their sensitivity to carboxin, fluopyram, and penthiopyrad. Seven SDHI resistance patterns were

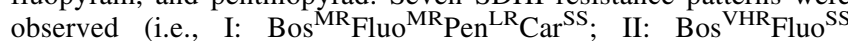
Pen ${ }^{\mathrm{MR}} \mathrm{Car}^{\mathrm{R}}$; III: Bos $^{\mathrm{LR}}$ Fluo ${ }^{\mathrm{MR}} \mathrm{Pen}^{\mathrm{LR}} \mathrm{Car}^{\mathrm{R}}$; IV: Bos $^{\mathrm{MR}} \mathrm{Fluo}^{\mathrm{MR}} \mathrm{Pen}^{\mathrm{MR}}$ $\mathrm{Car}^{\mathrm{R}}$; V: Bos ${ }^{\mathrm{HR}} \mathrm{Fluo}^{\mathrm{MR}} \mathrm{Pen}^{\mathrm{HR}} \mathrm{Car}^{\mathrm{R}}$; VI: Bos ${ }^{\mathrm{HR}} \mathrm{Fluo}^{\mathrm{HR}} \mathrm{Pen}^{\mathrm{HR}} \mathrm{Car}^{\mathrm{R}}$; and VII: Bos ${ }^{\mathrm{HR}}$ Fluo ${ }^{\mathrm{SS}} \mathrm{Pen}^{\mathrm{LR}} \mathrm{Car}^{\mathrm{R}}$, VHR: very highly resistant; HR: highly resistant; MR: moderately resistant; LR: low resistant; R: resistant; SS: supersensitive), corresponding to seven mutations in $s d h B / C / D$ genes, respectively.
\end{abstract}

Recently, Corynespora blight has become one of the most economically important plant diseases affecting cucumber ( $\mathrm{Li}$ et al. 2008). The causal agent, Corynespora cassiicola (Berk. \& M.A. Curtis) C.T. Wei, was first reported in 1906 in European countries (Gussow 1906). Cucumber is an important vegetable crop in China. In 2013, 1.17 million hectares were harvested and 54.4 million tons were produced, making China the largest producer of cucumber in the world (FAOSTAT; http://www.fao.org/faostat/en/\#home). $C$. cassiicola is known to infect more than 530 plant species from 380 genera in 53 families, including vegetables, such as cucumber, tomato, and cowpea, and cash crops, such as soybean, rubber, and cotton, resulting in huge economic losses in more than 70 countries (Dixon et al. 2009). This fungus was first discovered on cowpea in 1960 in China, then on cucumber, and spread rapidly and widely throughout cucumber-producing areas, especially those provinces around the Bohai Sea (Cha et al. 2009; Fang and Fu 1994; Gu et al. 2016; Liu et al. 2003; Qi et al. 1960; Wang et al. 2016; Yue 2010; Zeng et al. 2011; Zhang et al. 2014, 2015).

At present, management of Corynespora blight in cucumbers is primarily dependent on fungicide application. Studies have shown the effectiveness of many fungicides against $C$. cassiicola, including site-specific fungicides: sterol biosynthesis inhibitors (SBIs; e.g., prochloraz, difenoconazole, and tebuconazole), quinone outside inhibitors (QoIs; e.g., azoxystrobin and pyraclostrobin), succinate dehydrogenase

${ }^{\dagger}$ Corresponding author: B. Li; E-mail: libaojuivf@163.com

Fadi Zhu and Yanxia Shi contributed equally to this work and are considered co-first authors.

Funding: This work was supported by the National Natural Science Foundation of China (31401888), the Science and Technology Innovation Program of the Chinese Academy of Agricultural Sciences (CAAS-ASTIP-IVFCAAS), the Key Laboratory of Biology and Genetic Improvement of Horticultural Crops, Ministry of Agriculture, P. R. China, and the Modern Agro-industry Technology Research System in China (CARS-25).

*The $\boldsymbol{e}$-Xtra logo stands for "electronic extra" and indicates that four supplementary tables and five supplementary figures are published online.

Accepted for publication 28 June 2018.

(c) 2019 The American Phytopathological Society inhibitors (SDHIs; e.g., boscalid, fluopyram, and fluxapyroxad), methylbenzimidazole carbamates (MBC; carbendazim and thiophanatemethyl), phenylpyrroles (fludioxonil), dicarboxidmides (iprodione); multisite fungicides (chlorothalonil, mancozeb, thiram), and the host plant defense inductor benzo-thiadiazole (Huang 2012; Ji et al. 2010; Li et al. 2009; Pernezny et al. 2003; Qi et al. 2009; Schlub et al. 2009; Tang et al. 2008; Teramoto et al. 2011; Xu et al. 2000). Three chemical classes of site-specific fungicides are used for Corynespora blight management in China: SDHIs (fluopyram and fluxapyroxad), SBIs (tebuconazole, difenoconazole, and prochloraz), and QoIs (trifloxystrobin and azoxystrobin) (China Pesticide Information Network 2017). However, farmers from Liaoning and Shandong provinces have reported the failure of Luna Sensation (a prepacked mixture of fluopyram and trifloxystrobin) and have consulted with us regarding effective fungicides. We felt it necessary to make it clear whether the C. cassiicola population have developed resistance to fluopyram or other SDHI like boscalid.

Boscalid, as well as fluopyram, is widely used to fight fungal plant pathogens due to its broad-spectrum activity. Boscalid belongs to the SDHI class of fungicides, which inhibit cell energy production by binding to the ubiquinone-binding pocket of succinate dehydrogenase (complex II) and blocking mitochondrial electron transfer in the fungal respiration pathway (Ruprecht et al. 2009). SDHIs are classified as medium to high risk for resistance development due to their widespread use and the site-specific mode of action (McKay et al. 2011).

Boscalid is currently registered as an effective agent against Corynespora blight, though resistance of $C$. cassiicola populations in the field to boscalid was reported two years after its registration (Miyamoto et al. 2009). The resistance mechanism was found to be associated with several different point mutations in one of the subunits (B, C, or D) of the SDH complex. These mutations included the replacement of histidine (CAC) by tyrosine (TAC) or of histidine (CAC) by arginine (CGC) at amino acid position 278 (SdhB$\mathrm{H} 278 \mathrm{Y} / \mathrm{R}$ ) in the SdhB subunit; the replacement of serine (TCG) by proline (CCG) at position 73 (SdhC-S73P) in the SdhC subunit; and the replacement of serine (TCC) by proline (CCC) or of glycine (GGC) by valine (GTC) at position 89 (SdhD-S89P) or 109 in the SdhD (SdhD-G109V) subunit (Miyamoto et al. 2010). For isolates with different levels of resistance to boscalid, cross-resistance to other SDHIs differed. Positive cross-resistance to penthiopyrad was observed in $C$. cassiicola isolates resistant to boscalid. Lack of crossresistance to fluopyram was observed in highly boscalid-resistant isolates, while positive cross-resistance to fluopyram was found in 
moderately boscalid-resistant isolates (Ishii et al. 2011). In addition, resistance of $C$. cassiicola to other classes of fungicides, such as QoIs, benzimidazoles, and N-phenylcarbamates, has also been reported (Date et al. 2004; Hasama 1991). C. cassiicola is considered by FRAC groups to be a high-risk pathogen for fungicide resistance development (FRAC 2017). Boscalid-resistant isolates of Podosphaera xanthii, a powdery mildew fungus with a similarly high propensity for resistance development, were recently reported on cucumber in Japan, although boscalid was not registered for cucumber powdery mildew disease management (Ishii et al. 2011). Boscalid-resistant $C$. cassiicola isolates may have developed on cucumber in a manner similar to the boscalid-resistant isolates of powdery mildew fungus. We therefore conducted a study to determine whether boscalid remains effective at controlling Corynespora blight on cucumber in China.

Finally, the objectives of this study were (i) to establish the baseline sensitivity of Chinese $C$. cassiicola isolates to boscalid; (ii) to assess the occurrence and distribution of boscalid-resistant $C$. cassiicola isolates within field populations; (iii) to determine cross-resistance patterns to boscalid, fluopyram, penthiopyrad, and carboxin; and (iv) to investigate the point mutations in the $s d h B / C / D$ genes associated with resistance.

\section{Materials and Methods}

Fungal isolates. In total, 122 single-spore isolates of $C$. cassiicola (Supplementary Table S1) collected from different crops with no history of SDHI usage were used to determine baseline sensitivity for boscalid, by a mycelial growth inhibition assay on PDA.

For boscalid monitoring studies, 920 C. cassiicola single-spore isolates including the 122 isolates used for sensitivity baseline establishment were collected from 2005 to 2017 from different hosts (cucumber: 795 isolates; tomato: 53 isolates; and other hosts: 72 isolates) and areas (Fig. 1), including Beijing, Hebei, Henan, Liaoning, Shandong, Tianjin, and other provinces and cities.

In total, 37 C. cassiicola isolates from cucumber, with different levels of resistance to boscalid, were used to determine the crossresistance patterns to boscalid, fluopyram, penthiopyrad, and carboxin. These isolates were selected from Liaoning (14 isolates), Shandong (12 isolates), and Hebei (nine isolates) provinces and Beijing City (two isolates)

C. cassiicola was isolated from symptomatic cucumber leaves obtained from greenhouses or fields as described previously ( $\mathrm{Li}$ et al. 2014). Single spore isolation was conducted in a laminar flow cabinet as follows: first, a colony was picked and deposited into a 2-ml centrifuge tube containing $200 \mu \mathrm{l}$ sterilized distilled water; next, the tube was vortexed to obtain a spore suspension at $1 \times 10^{4}$ spores $/ \mathrm{ml} ; 0.1 \mu \mathrm{l}$

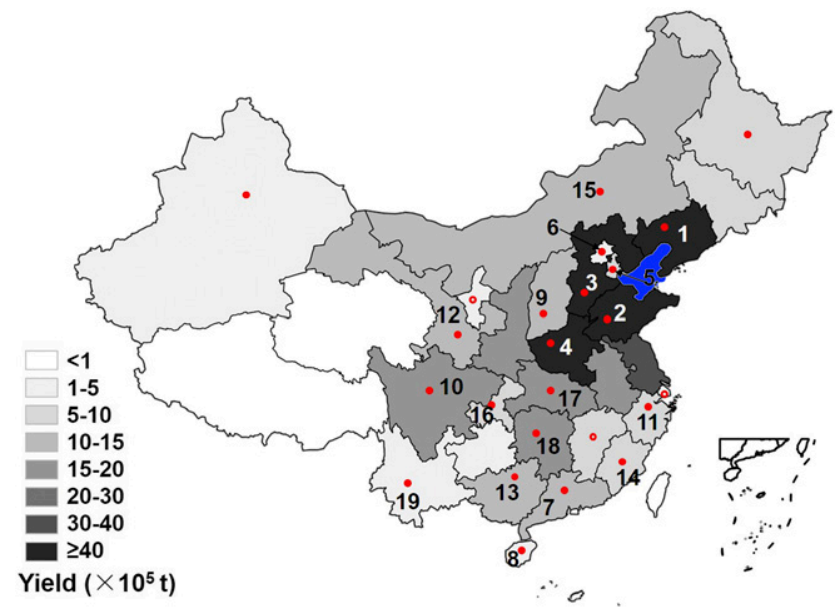

Fig. 1. Distribution of Corynespora cassiicola collected in China. Gradients represent different cucumber yields in 2014 in different provinces or cities in China. Dots represent populations of $C$. cassiicola that exist in these provinces by investigation of our research group, while circles represent other reports of Chinese researchers. Numbers represent 19 provinces or cities where C. cassiicola isolates were collected for fungicide sensitivity testing. Note: The blue area represents the Bohai Sea. suspension was pipetted on a cover slide for assessment under a microscope to guarantee the presence of only one spore in the microdroplet; the cover slide was placed droplet-side down on PDA plates and incubated at $26^{\circ} \mathrm{C}$ for 4 to 5 days (Supplementary Fig. S1); and finally, the colony around the cover slide was transferred to PDA slant for long-term storage at $4^{\circ} \mathrm{C}$.

Determination of baseline sensitivity and discriminatory dose. Technical grade boscalid (Shaanxi Meibang Pesticide Co., Ltd., China) stock solution of $50 \mathrm{mg} / \mathrm{ml}$ was prepared by dissolving the fungicide in $100 \%$ acetone. The stock solution was stored at $4{ }^{\circ} \mathrm{C}$ until use. For sensitivity testing, the boscalid stock solution was diluted in acetone and initially added to autoclaved YBA (Miyamoto et al. 2009), cooled to approximately $55^{\circ} \mathrm{C}$, as described in Table 1 , to obtain described concentrations. The control medium was not supplemented with boscalid, and the concentration of acetone in the boscalid-amended medium did not exceed $0.1 \%$. However, some isolates did not grow on YBA and some grew very little (Supplementary Fig. S2), while all isolates grew well on PDA. Therefore, PDA was chosen as the sensitivity test medium, with the same procedure as described. Three replicates of plates were used per concentration, and the experiment were conducted twice.

A radial growth method was adopted to determine the effective concentrations for $50 \%$ inhibition of mycelial growth $\left(\mathrm{EC}_{50}\right)$ of 122 C. cassiicola isolates from different crops with no history of SDHI usage. For each isolate, mycelial plugs $(5 \mathrm{~mm}$ in diameter) were obtained from the margins of actively growing colonies on 7-day-old PDA cultures using a cork borer and were placed onto the center of plates $(5.5 \mathrm{~cm}$ in diameter) made with boscalidsupplemented PDA. Each colony diameter (subtracting the diameter of the inoculation plug) was measured in two perpendicular directions after 5 days of incubation at $26^{\circ} \mathrm{C}$ in the dark. The $\mathrm{EC}_{50}$ value of each isolate was calculated by regressing the relative inhibition of mycelial growth against the $\log _{10}$ boscalid concentration (SAS 9.4; SAS Institute Inc.). The experiment was performed twice. Box plots were used to analyze the relative inhibition of mycelial growth at a given boscalid concentration, and a linear regression of the percent inhibition versus the $\log _{10}$ of the fungicide concentration was also performed by Sigma Plot 10.0 (Systat Software, InC). The discriminatory dose was determined as the concentration at which sensitive isolates grew less than $50 \%$ of the average colony diameter measured under control conditions, while resistant isolates grew without inhibition (FRAC, monograph 3).

Assessment of $\boldsymbol{C}$. cassiicola boscalid sensitivity in China. The boscalid sensitivity of 920 C. cassiicola isolates was quantified on PDA using mycelial growth inhibition at discriminatory dose and $\mathrm{EC}_{50}$ values. For discriminatory dose determination, all 122 isolates were less than $50 \%$ mycelial growth at $10 \mu \mathrm{g} / \mathrm{ml}$ or higher concentration of boscalid (technical grade, $97 \%$ a.i.), so $10 \mu \mathrm{g} / \mathrm{ml}$ could be used as the discriminatory dose; however, at the beginning of this study, we chose to test the sensitivity on PDA plates amended with two concentrations of 10 and $30 \mu \mathrm{g} / \mathrm{ml}$ of boscalid (Cantus, 50\% a.i. by weight, water-dispersible granule, BASF). The percent of mycelial growth inhibition was calculated for boscalid as (1 [boscalid-treated colony diameter/control colony diameter] $) \times 100$. Each mycelial plug ( $5 \mathrm{~mm}$ in diameter) from a 7-day-old culture of each isolate was placed in the center of a Petri dish $(5.5 \mathrm{~cm}$ diameter $)$ containing $5 \mathrm{ml}$ of PDA supplemented with boscalid at the discriminatory concentration. The PDA plates were incubated for 5 days at $26^{\circ} \mathrm{C}$ in the dark. The colony diameter of each isolate was measured using a ruler in two perpendicular directions. The experiment was randomized and for each isolate, two replicates with and without boscalid were used. The experiment was repeated twice. $\mathrm{EC}_{50}$ value determination for 798 isolates to boscalid (technical grade, $97 \%$ a.i.) was the same as described in the baseline sensitivity test.

Cross-resistance. Thirty-seven $C$. cassiicola isolates with different resistance levels to boscalid were tested for their sensitivities to penthiopyrad, fluopyram, and carboxin (Table 2). Each chemical was dissolved in acetone to obtain a $50 \mathrm{mg} / \mathrm{ml}$ stock solution. To obtain the desired experimental concentrations of each fungicide (Table 1), stock solutions were serially diluted in acetone. PDA 
was also used as the growth medium. The $\mathrm{EC}_{50}$ value for each fungicide-isolate combination was determined. To measure crossresistance between pairs of the SDHIs tested, the Pearson's correlation coefficient was estimated based on the $\log _{10} \mathrm{EC}_{50}$ values for each pair. Statistical analyses were performed using SPSS software (version 20.0; SPSS Inc., Chicago). Each isolate-fungicideconcentration combination was represented by two replicates, and the experiment was repeated twice.

Table 1. Test media, chemical names, manufacturers or providers, and fungicide concentrations for sensitivity testing

\begin{tabular}{llll}
\hline Medium & Chemical name & \multicolumn{1}{c}{ Manufacturers or providers } & Concentration $(\boldsymbol{\mu g} / \mathbf{m l})$ \\
\hline PDA & Boscalid 97\% & Shaanxi Meibang Pesticide Co., Ltd., China & $0,0.01,0.1,0.5,1,5,10,25,50$ \\
YBA & Boscalid 97\% & Shaanxi Meibang Pesticide Co., Ltd., China & $0,0.001,0.01,0.05,0.1,1,5$ \\
PDA & Carboxin 98\% & Guangxi Nanning Lvfeng Chemical Industry Co., Ltd., China & $0,0.01,0.1,0.5,1,5,10,25,50$ \\
PDA & Fluopyram 98\% & Junkai (Tianjin) Chemical Co., Ltd., China & $0,0.01,0.1,0.5,1,5,10,25,50$ \\
PDA & Penthiopyrad 98.8\% & Mitsui Chemicals Agro., Inc., Japan & $0,0.01,0.1,0.5,1,5,10,25,50$ \\
\hline
\end{tabular}

Table 2. The concentration that results in $50 \%$ mycelial growth inhibition $\left(\mathrm{EC}_{50}\right.$ values) to four technical grade succinate dehydrogenase inhibitors (SDHIs) and the deduced amino acid substitution in succinate dehydrogenase (SDH) of 37 isolates of Corynespora cassiicola

\begin{tabular}{|c|c|c|c|c|c|c|c|c|c|}
\hline \multirow[b]{2}{*}{ Isolate } & \multirow[b]{2}{*}{ Location } & \multicolumn{4}{|c|}{$\mathrm{EC}_{50}(\mu \mathrm{g} / \mathrm{ml})^{\mathrm{a}}$} & \multirow[b]{2}{*}{ Resistant type $^{f}$} & \multicolumn{3}{|c|}{$\begin{array}{l}\text { Deduced substitution in } \\
\text { SDH subunits }\end{array}$} \\
\hline & & Boscalid $^{b}$ & Fluopyrame & Penthiopyrad $^{\mathrm{d}}$ & Carboxin $^{\mathrm{e}}$ & & SdhB & SdhC & SdhD \\
\hline HG14102422-4 & Cangzhou, Hebei & $\mathrm{S}(1.13)$ & S (2.63) & $\mathrm{S}(0.36)$ & S (19.10) & $S$ & WT & WT & WT \\
\hline HG14102430-1 & Cangzhou, Hebei & VHR $(>>50)$ & SS (2.62) & MR (19.36) & $\mathrm{R}(>50)$ & II & $\mathrm{H} 278 \mathrm{Y}$ & WT & WT \\
\hline HG14102526-4 & Langfang, Hebei & S (1.07) & S (2.44) & $\mathrm{S}(0.31)$ & S (17.28) & S & WT & WT & WT \\
\hline HG14102526-5 & Langfang, Hebei & VHR $(>>50)$ & SS (1.35) & MR (19.49) & $\mathrm{R}(>50)$ & II & $\mathrm{H} 278 \mathrm{Y}$ & WT & WT \\
\hline HG16010707-1 & Tangshan, Hebei & S (1.16) & S (2.20) & $\mathrm{S}(0.37)$ & S (16.69) & $\mathrm{S}$ & - & - & - \\
\hline HG16010608-2 & Tangshan, Hebei & MR (19.15) & MR (20.19) & LR (3.56) & SS (11.44) & I & WT & S73P & WT \\
\hline HG16010708-9g & Tangshan, Hebei & MR (11.19) & MR (8.42) & LR (2.65) & SS (7.29) & $\mathbf{I}$ & WT & S73P & WT \\
\hline HG1601060705 & Tangshan, Hebei & VHR $(>>50)$ & SS (2.56) & MR (21.32) & $\mathrm{R}(>50)$ & II & $\mathrm{H} 278 \mathrm{Y}$ & WT & WT \\
\hline HG16010708-3 & Tangshan, Hebei & VHR $(>>50)$ & SS (2.15) & MR (21.19) & $\mathrm{R}(>50)$ & II & $\mathrm{H} 278 \mathrm{Y}$ & WT & WT \\
\hline HG15041361-2 & Shouguang, Shandong & $\mathrm{S}(1.21)$ & $\mathrm{S}(2.38)$ & $\mathrm{S}(0.50)$ & S (19.95) & S & WT & WT & WT \\
\hline HG15041351-2 & Shouguang, Shandong & MR (17.35) & MR (27.20) & MR (23.58) & $\mathrm{R}(>50)$ & IV & WT & WT & D95E \\
\hline HG15041351-1 & Shouguang, Shandong & VHR $(>>50)$ & SS (1.38) & MR (15.91) & $\mathrm{R}(>50)$ & II & $\mathrm{H} 278 \mathrm{Y}$ & WT & WT \\
\hline HG15041321-2 & Shouguang, Shandong & $\mathrm{S}(1.24)$ & $\mathrm{S}(2.24)$ & $\mathrm{S}(0.22)$ & S (11.19) & S & WT & WT & WT \\
\hline HG15041311-1 & Shouguang, Shandong & VHR $(>>50)$ & SS (1.79) & MR (20.41) & $\mathrm{R}(>50)$ & II & $\mathrm{H} 278 \mathrm{Y}$ & WT & WT \\
\hline HG15051328-4 & Linyi, Shandong & $\mathrm{S}(\mathbf{1 . 3 1})$ & $\mathrm{S}(\mathbf{1 . 4 0 )}$ & $\mathrm{S}(\mathbf{0 . 3 2})$ & $\mathrm{S}(\mathbf{8 . 9 6 )}$ & $\mathbf{S}$ & WT & WT & WT \\
\hline HG15051304-3 & Linyi, Shandong & $\mathrm{S}(2.12)$ & S (1.93) & $\mathrm{S}(0.75)$ & S (15.00) & $\mathrm{S}$ & WT & WT & WT \\
\hline HG15051314-1-2 & Linyi, Shandong & S (0.92) & $\mathrm{S}(1.72)$ & $\mathrm{S}(0.25)$ & S (18.56) & $\mathrm{S}$ & WT & WT & WT \\
\hline HG15051320-1 & Linyi, Shandong & $\operatorname{VHR}(>>50)$ & SS (1.18) & MR (13.17) & $\mathrm{R}(>50)$ & II & $\mathrm{H} 278 \mathrm{Y}$ & WT & WT \\
\hline HG15051409-1 & Linyi, Shandong & S (0.94) & $\mathrm{S}(3.71)$ & $\mathrm{S}(0.65)$ & $\mathrm{S}(13.81)$ & $\mathrm{S}$ & WT & WT & WT \\
\hline HG15051406-4 & Linyi, Shandong & MR (22.5) & MR (21.26) & LR (9.02) & SS (11.38) & I & WT & S73P & WT \\
\hline HG15051414-2 & Linyi, Shandong & $\operatorname{VHR}(>>50)$ & SS (1.92) & MR (28.38) & $\mathrm{R}(>50)$ & II & $\mathrm{H} 278 \mathrm{Y}$ & WT & WT \\
\hline HG15050755-3 & Lingyuan, Liaoning & S (1.70) & S (1.63) & $\mathrm{S}(0.30)$ & $\mathrm{S}(12.05)$ & S & WT & WT & WT \\
\hline HG15050755-1 & Lingyuan, Liaoning & $\mathrm{S}(1.34)$ & $\mathrm{S}(1.52)$ & $\mathrm{S}(0.25)$ & $\mathrm{S}(12.15)$ & $\mathrm{S}$ & WT & WT & WT \\
\hline HG15050825-6 & Lingyuan, Liaoning & LR (6.13) & $\operatorname{MR}(>50)$ & LR (3.50) & $\mathrm{R}(39.54)$ & III & $\mathrm{I} 280 \mathrm{~V}$ & WT & WT \\
\hline HG15050825-3 & Lingyuan, Liaoning & LR (5.07) & $\operatorname{MR}(>50)$ & LR (2.52) & $\mathrm{R}(36.11)$ & III & $\mathrm{I} 280 \mathrm{~V}$ & WT & WT \\
\hline HG15050729-5 & Lingyuan, Liaoning & LR (4.19) & $\operatorname{MR}(>50)$ & LR (3.40) & $\mathrm{R}(37.42)$ & III & $\mathrm{I} 280 \mathrm{~V}$ & WT & WT \\
\hline HG15050748-1 & Lingyuan, Liaoning & LR (2.55) & MR (8.46) & LR (2.05) & R (26.63) & III & $\mathrm{I} 280 \mathrm{~V}$ & WT & WT \\
\hline HG15050737-1 & Lingyuan, Liaoning & LR (6.59) & MR (>50) & LR (3.20) & $\mathrm{R}(>50)$ & III & $\mathrm{I} 280 \mathrm{~V}$ & WT & WT \\
\hline HG15050806 & Lingyuan, Liaoning & MR (13.8) & MR (14.26) & LR (2.18) & SS (9.22) & I & WT & S73P & WT \\
\hline HG15050752-7 & Lingyuan, Liaoning & MR (7.25) & MR (5.09) & LR (1.18) & SS (6.90) & I & WT & S73P & WT \\
\hline HG15050714-10 & Lingyuan, Liaoning & MR (20.28) & MR (22.58) & LR (2.67) & SS (9.65) & I & WT & S73P & WT \\
\hline HG15050701-1 & Lingyuan, Liaoning & MR (23.02) & MR (21.21) & LR (2.73) & SS (10.97) & I & WT & S73P & WT \\
\hline HG15050748-2 & Lingyuan, Liaoning & $\operatorname{HR}(>50)$ & MR (15.95) & $\operatorname{HR}(>50)$ & $\mathrm{R}(>50)$ & $\mathrm{V}$ & WT & WT & H105R \\
\hline HG15050725-18 & Lingyuan, Liaoning & $\mathrm{HR}(>50)$ & $\mathrm{HR}(>>50)$ & $\mathrm{HR}(>50)$ & $\mathrm{R}(>50)$ & VI & WT & WT & G105V \\
\hline HG15050740-4 & Lingyuan, Liaoning & $\operatorname{VHR}(>>50)$ & SS (1.12) & MR (21.97) & $\mathrm{R}(>50)$ & II & $\mathrm{H} 278 \mathrm{Y}$ & WT & WT \\
\hline HG17031007-2 & Daxing, Beijing & $\mathrm{S}(2.05)$ & $\mathrm{S}(1.41)$ & $\mathrm{S}(0.80)$ & $\mathrm{S}(18.32)$ & S & WT & WT & WT \\
\hline HG17031009-5 & Daxing, Beijing & $\mathrm{HR}(>50)$ & SS (1.25) & LR (2.78) & $\mathrm{R}(>50)$ & VII & $\mathrm{H} 278 \mathrm{R}$ & WT & WT \\
\hline
\end{tabular}

${ }^{a} \mathrm{EC}_{50}$ values were determined on potato dextrose agar (PDA) plates amended with boscalid (technical grade, $97 \%$ a.i.).

${ }^{\mathrm{b}}$ Phenotype of sensitivity to SDHI fungicide boscalid. $\mathrm{S}=$ sensitive $\left(\mathrm{EC}_{50}=0.92\right.$ to $\left.2.12 \mu \mathrm{g} / \mathrm{ml}\right), \mathrm{LR}=$ low resistant $(\mathrm{EC} 50=4.19$ to $6.59 \mu \mathrm{g} / \mathrm{ml}), \mathrm{MR}=\mathrm{mod}-$ erately resistant $\left(\mathrm{EC}_{50}=13.8\right.$ to $\left.23.02 \mu \mathrm{g} / \mathrm{ml}\right), \mathrm{HR}=$ highly resistant $\left(\mathrm{EC}_{50}>50 \mu \mathrm{g} / \mathrm{ml}\right)$, VHR $=$ very highly resistant $\left(\mathrm{EC}_{50}>50 \mu \mathrm{g} / \mathrm{ml}\right)$.

${ }^{c}$ Phenotype of sensitivity to SDHI fungicide fluopyram. SS = highly sensitive $\left(\mathrm{EC}_{50}=1.12\right.$ to $\left.2.62 \mu \mathrm{g} / \mathrm{ml}\right), \mathrm{S}=\operatorname{sensitive}\left(\mathrm{EC}_{50}=1.52\right.$ to $\left.3.71 \mu \mathrm{g} / \mathrm{ml}\right), \mathrm{MR}=$ moderately resistant $\left(\mathrm{EC}_{50}=14.26\right.$ to $\left.>50 \mu \mathrm{g} / \mathrm{ml}\right), \mathrm{HR}=$ highly resistant $\left(\mathrm{EC}_{50}>>50 \mu \mathrm{g} / \mathrm{ml}\right)$.

d Phenotype of sensitivity to SDHI fungicide penthiopyrad. $\mathrm{S}=$ sensitive $\left(\mathrm{EC}_{50}=0.22\right.$ to $\left.0.75 \mu \mathrm{g} / \mathrm{ml}\right), \mathrm{LR}=$ low resistant $\left(\mathrm{EC}_{50}=2.18\right.$ to $\left.9.02 \mu \mathrm{g} / \mathrm{ml}\right), \mathrm{MR}=$ moderately resistant $\left(\mathrm{EC}_{50}=13.17\right.$ to $\left.28.38 \mu \mathrm{g} / \mathrm{ml}\right), \mathrm{HR}=$ highly resistant $\left(\mathrm{EC}_{50}>50 \mu \mathrm{g} / \mathrm{ml}\right)$.

${ }^{\mathrm{e}}$ Phenotype of sensitivity to SDHI fungicide carboxin. SS = highly sensitive $\left(\mathrm{EC}_{50}=6.9\right.$ to $\left.11.44 \mu \mathrm{g} / \mathrm{ml}\right), \mathrm{S}=$ sensitive $\left(\mathrm{EC}_{50}=8.96\right.$ to $\left.19.95 \mu \mathrm{g} / \mathrm{ml}\right), \mathrm{R}=\mathrm{resistant}$ $\left(\mathrm{EC}_{50}>25 \mu \mathrm{g} / \mathrm{ml}\right)$.

${ }^{\mathrm{f}}$ I, II, III, IV, V, VI, and VII = Bos ${ }^{\mathrm{MR}}$ Fluo $^{\mathrm{MR}}{ }^{\mathrm{Pen}}{ }^{\mathrm{LR}} \mathrm{Car}^{\mathrm{SS}}$; Bos $^{\mathrm{VHR}}{ }^{\mathrm{Fluo}}{ }^{\mathrm{SS}} \mathrm{Pen}^{\mathrm{MR}} \mathrm{Car}^{\mathrm{R}}$; Bos $^{\mathrm{LR}} \mathrm{Fluo}^{\mathrm{MR}} \mathrm{Pen}^{\mathrm{LR}} \mathrm{Car}^{\mathrm{R}}$; Bos $^{\mathrm{MR}} \mathrm{Fluo}^{\mathrm{MR}} \mathrm{Pen}^{\mathrm{MR}} \mathrm{Car}^{\mathrm{R}}$; Bos ${ }^{\mathrm{HR}}$ Fluo $^{\mathrm{MR}}$ $\mathrm{Pen}^{\mathrm{HR}} \mathrm{Car}^{\mathrm{R}}$; $\mathrm{Bos}^{\mathrm{HR}} \mathrm{Fluo}^{\mathrm{HR}} \mathrm{Pen}^{\mathrm{HR}} \mathrm{Car}^{\mathrm{R} ;}$ and $\mathrm{Bos}^{\mathrm{HR}} \mathrm{Fluo}^{\mathrm{SS}} \mathrm{Pen}^{\mathrm{LR}} \mathrm{Car}^{\mathrm{R}}$, respectively.

${ }^{\mathrm{g}}$ Four isolates in bold were omitted for phenotype of sensitivity determination because their colony diameters were measured $36 \mathrm{~h}$ earlier than other isolates.

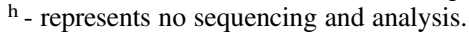


Determination of mutations in the $s d h B / C / D$ gene. The identification of $s d h B / C / D$ mutations was carried out on 189 isolates with different levels of resistance to boscalid. To extract DNA, these isolates were grown on PDA plates for 7 days at $26^{\circ} \mathrm{C}$ in the dark. Genomic DNA was extracted from $20 \mathrm{mg}$ of mycelium, as described by Plant Genomic DNA Kit (DP305, TIANGEN Biotech (Beijing) Co., Ltd). The primer pairs B-67(F)/B-1032(R), C-197 (F)/C-599(R), which were designed with Primer Premier 5 according to the complete cds sequence of $s d h B / C$ gene (AB548738.1 and AB548741.1) released in the NCBI by Miyamoto et al. (2010), and KES 862(F)/KES 762(R) (reported by Miyamoto et al. 2010) were used to amplify fragments of the $s d h B / C / D$ genes (Supplementary Table S2). Polymerase chain reaction (PCR) was performed in a final volume of $50 \mu$ l containing $25 \mu \mathrm{l} 2 \times$ Taq PCR MasterMix (Biomed, Taq DNA Polymerase [recombinant]: 0.05 units $/ \mu \mathrm{l} ; \mathrm{MgCl}_{2}: 4 \mathrm{mM}$; dNTPs [dATP, dCTP, dGTP, dTTP]: $0.4 \mathrm{mM}$ ), $4 \mu \mathrm{l}$ of DNA template $(50 \mathrm{ng} / \mu \mathrm{l}), 2 \mu \mathrm{l}$ of $10 \mu \mathrm{M}$ each primer, and $17 \mu \mathrm{lof} \mathrm{ddH}_{2} \mathrm{O}$. The PCR amplification program consisted of an initial denaturation at $94^{\circ} \mathrm{C}$ for $5 \mathrm{~min} ; 35$ cycles of $94^{\circ} \mathrm{C}$ for $45 \mathrm{~s}, 58^{\circ} \mathrm{C}$ for $45 \mathrm{~s}$, and $72^{\circ} \mathrm{C}$ (for $s d h B / D, 1 \mathrm{~min}$; for $s d h C, 30 \mathrm{~s}$ ); and a final 5-min elongation step at $72^{\circ} \mathrm{C}$ in an $\mathrm{S} 1000$ Thermal Cycler (BioRad).

Aliquots of $5 \mu \mathrm{l}$ of the PCR products were separated by electrophoresis on a $1 \%$ agarose gel and purified from the gel using a gel extraction kit (TIANGEN). Sequencing was performed by Biomad

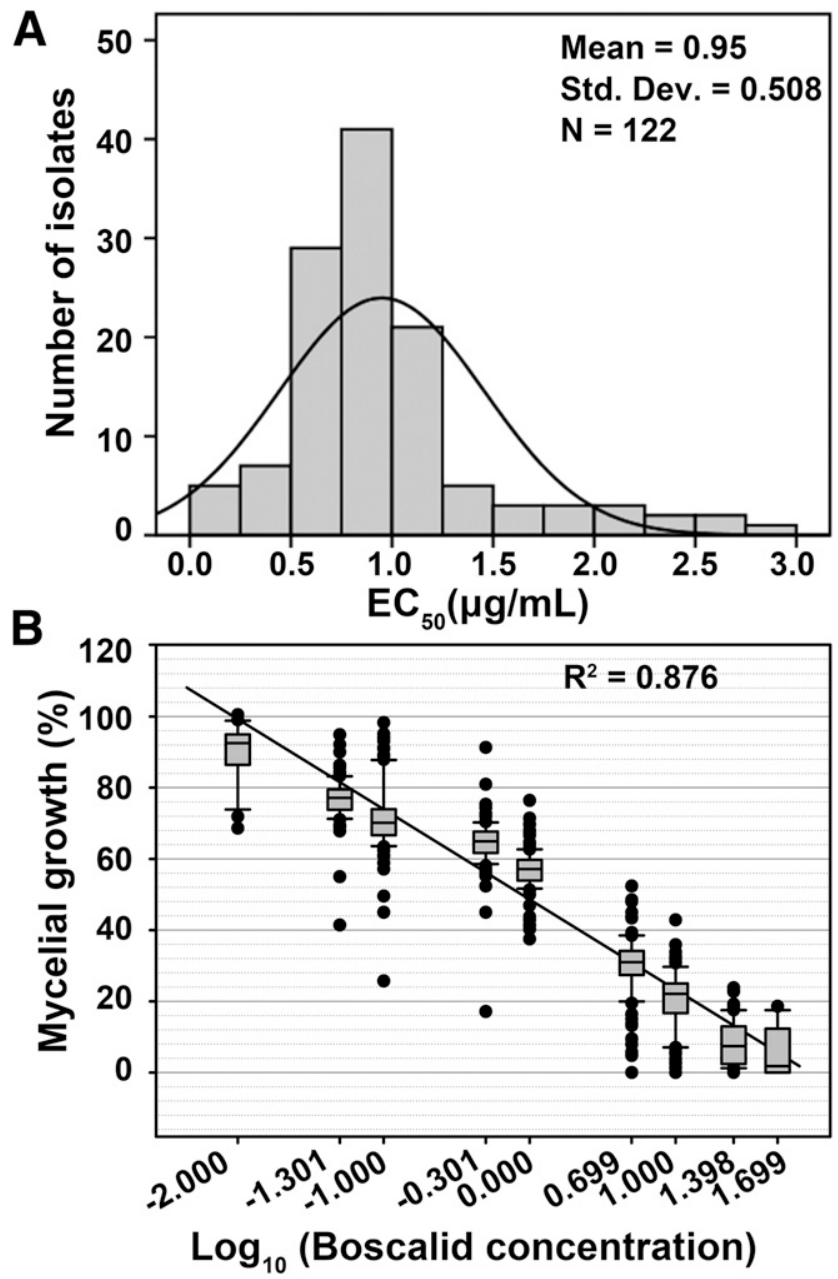

Fig. 2. Sensitivity distribution and mycelial growth of the 122 Corynespora cassiicola isolates in each boscalid (technical grade, 97\%) concentration. A, Sensitivity distribution of $\mathrm{EC}_{50}$ values of $C$. cassiicola isolates treated with boscalid based on mycelial growth, which is unimodal with a right-hand tail, ranges from $0.03 \mu \mathrm{g} / \mathrm{ml}$ to $2.85 \mu \mathrm{g} / \mathrm{ml}$ with an average $\mathrm{EC}_{50}$ value of $0.95 \pm 0.51 \mu \mathrm{g} / \mathrm{ml}$. B, Box plots showing the mycelial growth of the $C$. cassiicola isolates in each boscalid concentration. In the presence of boscalid at $10 \mu \mathrm{g} / \mathrm{ml}$ or higher concentration, all $C$. cassiicola isolates grew less than $50 \%$ relative to the control, so the discriminatory concentration of boscalid could be defined as $10 \mu \mathrm{g} / \mathrm{ml}$.
(BigDye Terminator ready reaction mix v31; Applied Biosystems). Sequences were submitted to GenBank under accession numbers MG729602 to MG729623. Sequences were analyzed using the computer sequence analysis software DNASTAR (DNASTAR, Inc.).

\section{Results}

Baseline sensitivity and discriminatory dose. A mycelial growth inhibition assay was used to determine the boscalid (technical grade, 97\%) sensitivities of 122 C. cassiicola isolates collected from different crops with no history of SDHI usage in China. In the beginning, YBA was used as our test medium; however, after 5 days of incubation at $26^{\circ} \mathrm{C}$ in the dark, four of the 56 isolates could not grow and another four exhibited very little growth on the YBA plates in the absence of fungicide in our initial sensitivity test. Isolates grew significantly slower on YBA (average colony growth: $2.69 \pm 0.52 \mathrm{~cm}$ ) than on PDA (average colony growth: $3.70 \pm 0.43 \mathrm{~cm}$ ) in the absence of fungicide. Based on these observations, PDA was finally selected for boscalid sensitivity tests as described previously (Amiri et al. 2014; Kim and Xiao 2010).

The 122 C. cassiicola isolates that were tested exhibited a unimodal distribution with a right-hand tail of $\mathrm{EC}_{50}$ values in response to boscalid (technical grade, 97\%) (Fig. 2A). The $\mathrm{EC}_{50}$ values of the 122 isolates ranged from 0.03 to $2.85 \mu \mathrm{g} / \mathrm{ml}$ with an average $\mathrm{EC}_{50}$ value of $0.95 \pm 0.51 \mu \mathrm{g} / \mathrm{ml}$. In the presence of boscalid at $10 \mu \mathrm{g} /$ $\mathrm{ml}$ or higher concentration, all of the 122 C. cassiicola isolates grew less than $50 \%$ relative to the control (Fig. 2B). Therefore, $10 \mu \mathrm{g} / \mathrm{ml}$ could be used as the discriminatory concentration for boscalid (technical grade). However, in the early stage of monitoring test, we didn't get enough technical-grade boscalid. A final discriminatory concentration of $30 \mu \mathrm{g} / \mathrm{ml}$ was determined for further monitoring in this study by a pretest which was conducted under two trial concentrations of 10 and $30 \mu \mathrm{g} / \mathrm{ml}$ prepared using a commercially formulated fungicide containing boscalid (Cantus 50WDG). Isolates exhibiting mycelial growth less than $40 \%$ at $30 \mu \mathrm{g} / \mathrm{ml}$ of boscalid were defined as sensitive, while isolates exhibiting more than $40 \%$ mycelial growth were defined as resistant (Supplementary Table S3, Supplementary Fig. S3 and S4).

Sensitivity of $\boldsymbol{C}$. cassiicola to boscalid in China. The $\mathrm{EC}_{50}$ values and mycelial growth inhibition under discriminatory dose of $798 C$. cassiicola isolates to boscalid determined in this study showed that $27.8 \%$ were resistant (Fig. 3). According to the $\mathrm{EC}_{50}$ values, these resistant isolates has been divided into four groups: $2.8 \%$ low resistant (LR) isolates, with $\mathrm{EC}_{50}$ values ranging from 4.20 to $6.88 \mu \mathrm{g} / \mathrm{ml}$ and a mean of $5.57 \mu \mathrm{g} / \mathrm{ml} ; 11.5 \%$ moderately resistant (MR), with $\mathrm{EC}_{50}$ values ranging from 11.19 to $24.67 \mu \mathrm{g} / \mathrm{ml}$, a mean of $19.17 \mu \mathrm{g} / \mathrm{ml}$; $1.4 \%$ highly resistant (HR), with $\mathrm{EC}_{50}$ values ranging from 36.98 to $>50 \mu \mathrm{g} / \mathrm{ml}$; and $12.2 \%$ very highly resistant (VHR) isolates, with $\mathrm{EC}_{50}$ values $>50 \mu \mathrm{g} / \mathrm{ml}$. Compared with the sensitivity baseline, $\mathrm{EC}_{50}$ value distribution of the remaining isolates $(72.2 \%)$ were between 0.54 and $3.33 \mu \mathrm{g} / \mathrm{ml}$, with an average of $1.43 \mu \mathrm{g} / \mathrm{ml}$; though slightly right shifted, they were still under the sensitivity baseline (Fig. 3A), thus defined as sensitive (S).

The frequency distributions of $\mathrm{EC}_{50}$ values of isolates from different hosts were different. Isolates from cucumber were divided into five groups (S: 0.11 to $3.33 \mu \mathrm{g} / \mathrm{ml}, \mathrm{LR}$ : 4.20 to $6.88 \mu \mathrm{g} / \mathrm{ml}, \mathrm{MR}$ : 11.19 to $24.67 \mu \mathrm{g} / \mathrm{ml}$, HR: 34.58 to $>50 \mu \mathrm{g} / \mathrm{ml}$, and VHR: $>>50 \mu \mathrm{g} / \mathrm{ml}$ ) according to the frequency distribution of $\mathrm{EC}_{50}$ values (Fig. 4A), isolates from tomato were separated into two groups of $\mathrm{S}$ and HR (Fig. 4B, S: 0.71 to $2.23 \mu \mathrm{g} / \mathrm{ml}$, HR: $>50 \mu \mathrm{g} / \mathrm{ml}$ ), isolates from other hosts consisted of only one sensitive group (Fig. 4C, S: 0.03 to $2.85 \mu \mathrm{g} / \mathrm{ml})$. The frequency distributions of $\mathrm{EC}_{50}$ values of isolates from cucumber from different years were also different. Isolates from cucumber collected before 2014 turned out to be sensitive (Fig. 4D, S: 0.11 to $2.58 \mu \mathrm{g} / \mathrm{ml}$ ), while after 2014 were divided into five groups (Fig. 4E, S: 0.92 to $3.33 \mu \mathrm{g} / \mathrm{ml}$; LR: 4.20 to $6.88 \mu \mathrm{g} / \mathrm{ml}$; MR: 11.19 to $24.67 \mu \mathrm{g} / \mathrm{ml}$; HR: 34.58 to $>50 \mu \mathrm{g} / \mathrm{ml}$; VHR: $>>50$ $\mu \mathrm{g} / \mathrm{ml})$. The frequency distributions of $\mathrm{EC}_{50}$ values for the $C$. cassiicola population obtained from cucumber from different provinces or cities differed a lot. Isolates collected from Shandong (Fig. 4F) and Hebei provinces (Fig. 4G) were divided into three groups, namely 
S (Shandong: 0.27 to $2.15 \mu \mathrm{g} / \mathrm{ml}$; Hebei: 0.11 to $2.63 \mu \mathrm{g} / \mathrm{ml}$ ), MR (Shangdong: 15.08 to $24.67 \mu \mathrm{g} / \mathrm{ml}$; Hebei: 11.19 to $23.76 \mu \mathrm{g} / \mathrm{ml}$ ), and VHR (both provinces: $>>50 \mu \mathrm{g} / \mathrm{ml}$ ). Isolates from Liaoning Province (Fig. 4H) were divided into five groups (S: 0.45 to $1.70 \mu \mathrm{g} / \mathrm{ml}$; LR: 4.20 to $6.88 \mu \mathrm{g} / \mathrm{ml}$; MR: 13.26 to $24.12 \mu \mathrm{g} / \mathrm{ml}$; HR: $>50 \mu \mathrm{g} / \mathrm{ml}$; and VHR: $>50 \mu \mathrm{g} / \mathrm{ml}$ ). Isolates from Beijing (Fig. 4I) were also separated: one sensitive group with $\mathrm{EC}_{50}$ values ranged from 0.79 to $1.56 \mu \mathrm{g} / \mathrm{ml}$, and one HR group with $\mathrm{EC}_{50}$ values ranged from 34.58 to $46.94 \mu \mathrm{g} / \mathrm{ml}$. The $\mathrm{EC}_{50}$ values of isolates collected from Tianjin city (Fig. $4 \mathrm{~J}$ ) were even more separated: one ranged from 1.11 to $3.33 \mu \mathrm{g} / \mathrm{ml}$ (S), the second was between 13.30 and $17.86 \mu \mathrm{g} / \mathrm{ml}$ (MR), and the third one was $>>50 \mu \mathrm{g} / \mathrm{ml}$ (VHR). The $\mathrm{EC}_{50}$ values of isolates collected from Henan Province (Fig. $4 \mathrm{~K})$ were divided into two groups: one was between 0.34 and $1.21 \mu \mathrm{g} / \mathrm{ml}$ (S) and the other $>>50 \mu \mathrm{g} / \mathrm{ml}$ (VHR). The $\mathrm{EC}_{50}$ values of all the isolates collected from other provinces (Fig. 4L) were between 0.44 and $2.58 \mu \mathrm{g} / \mathrm{ml}(\mathrm{S})$.

Comparing the mycelial growth inhibition (MGI) and $\mathrm{EC}_{50}$ values, we found that the MGIs at the discriminatory dose for isolates in the groups of S, LR, MR, HR, and VHR were $>60 \%, 51.5$ to $59.7 \%$, 27.0 to $49.7 \%, 19.6$ to $28.2 \%$, and 2.5 to $25.0 \%$, respectively. Obviously, overlaps for MGIs have occurred between groups of VHR and $\mathrm{HR}$, and $\mathrm{HR}$ and MR, demonstrating a weaker distinguishing ability compared with the $\mathrm{EC}_{50}$ values. However, by analyzing the MGI distribution of 798 isolates, we have obtained two resistant populations, namely the MR (about $35 \pm 10 \%$ ) and VHR (about $15 \pm$ $10 \%$ ), respectively (Fig. 3C). Thus, we concluded that the discriminatory methods can also be applied to monitor the total field frequency of boscalid resistance in $C$. cassiicola population; however, this is indistinct compared with $\mathrm{EC}_{50}$ values.

Cross-resistance. Based on the $\mathrm{EC}_{50}$ values and mycelial growth inhibition on PDA at $50 \mu \mathrm{g} / \mathrm{ml}$ of each SDHI tested, the 37 C. cassiicola isolates were divided into seven different fungicide resistance patterns (Table 2, Fig. 5, Supplementary Fig. S5): pattern I (Bos ${ }^{\text {MR }}$ Fluo ${ }^{\mathrm{MR}} \mathrm{Pen}^{\mathrm{LR}} \mathrm{Car}^{\mathrm{SS}}$, MR: moderately resistant, LR: low resistant, SS: supersensitive), pattern II (Bos ${ }^{\mathrm{VHR}}$ Fluo $^{\mathrm{SS}} \mathrm{Pen}^{\mathrm{MR}} \mathrm{Car}^{\mathrm{R}}$, VHR: very highly resistant, R: resistant), pattern III $\left(\operatorname{Bos}^{\mathrm{LR}} \mathrm{Fluo}^{\mathrm{MR}} \mathrm{Pen}^{\mathrm{LR}} \mathrm{Car}^{\mathrm{R}}\right)$, pattern IV $\left(\right.$ Bos $\left.^{\mathrm{MR}} \mathrm{Fluo}^{\mathrm{MR}} \mathrm{Pen}^{\mathrm{MR}} \mathrm{Car}^{\mathrm{R}}\right)$, pattern $\mathrm{V}\left(\mathrm{Bos}^{\mathrm{HR}} \mathrm{Fluo}^{\mathrm{MR}}\right.$ Pen ${ }^{\mathrm{HR}} \mathrm{Car}^{\mathrm{R}}$, HR: highly resistant), pattern VI $\left(\mathrm{Bos}^{\mathrm{HR}} \mathrm{Fluo}^{\mathrm{HR}} \mathrm{Pen}^{\mathrm{HR}}\right.$ $\mathrm{Car}^{\mathrm{R}}$ ), and pattern VII (Bos ${ }^{\mathrm{HR}}$ Fluo $\left.{ }^{\mathrm{SS}} \mathrm{Pen}^{\mathrm{LR}} \mathrm{Car}^{\mathrm{R}}\right)$. Patterns I and II were observed in all three provinces studied; pattern IV was only observed in Shandong Province; pattern VII was only discovered in Beijing; and patterns III, V, and VI were only observed in Liaoning Province.

Cross-resistance between boscalid and carboxin, penthiopyrad, or fluopyram were analyzed based on the $\mathrm{EC}_{50}$ values for these four SDHIs of 37 C. cassiicola isolates collected from Liaoning, Hebei, and Shandong provinces and Beijing and exhibited different resistance levels to boscalid (Table 2). Regression analyses (Fig. 6) and Pearson correlation tests revealed no significant cross-resistance between boscalid and fluopyram $(\mathrm{r}=-0.029, P=0.864, n=37$ ) (Fig. $6 \mathrm{~A}$ ), while strong correlations were observed between boscalid and penthiopyrad ( $\mathrm{r}=0.800, P<0.001, n=37$ ) (Fig. 6B) and between boscalid and carboxin $(\mathrm{r}=0.789, P<0.001, n=37)$ (Fig. 6C). However, significant positive cross-resistance was observed between boscalid and fluopyram ( $\mathrm{r}=0.822, P<0.001, n=27$ ) (Fig. 6D), as well as boscalid and penthiopyrad $(\mathrm{r}=0.904, P<0.001, n=27)$ (Fig. 6E), but not between boscalid and carboxin $(\mathrm{r}=0.224, P=$ $0.261, n=27$ ) (Fig. 6F), in a separate analysis of the 27 isolates sensitive or moderate or high resistant to boscalid.

Detection of $s d h B / C / D$ mutations in $C$. cassiicola isolates. One hundred and eighty-nine isolates were selected for $s d h B / C / D$ sequencing. Results showed several mutations in these isolates (Supplementary Table S4). The substitution from serine to proline at position 73 in SdhC (SdhC-S73P) was found in 26 isolates moderately resistant to boscalid. Substitution of histidine with tyrosine or arginine at amino acid position 278 in $\mathrm{SdhB}$ (SdhB-H278Y/R) was respectively detected in 28 very highly resistant isolates and one highly resistant isolate. Substitution from isoleucine to valine at amino acid position 280 in SdhB (SdhB- I280V, ATT $\rightarrow$ GTT) was
A

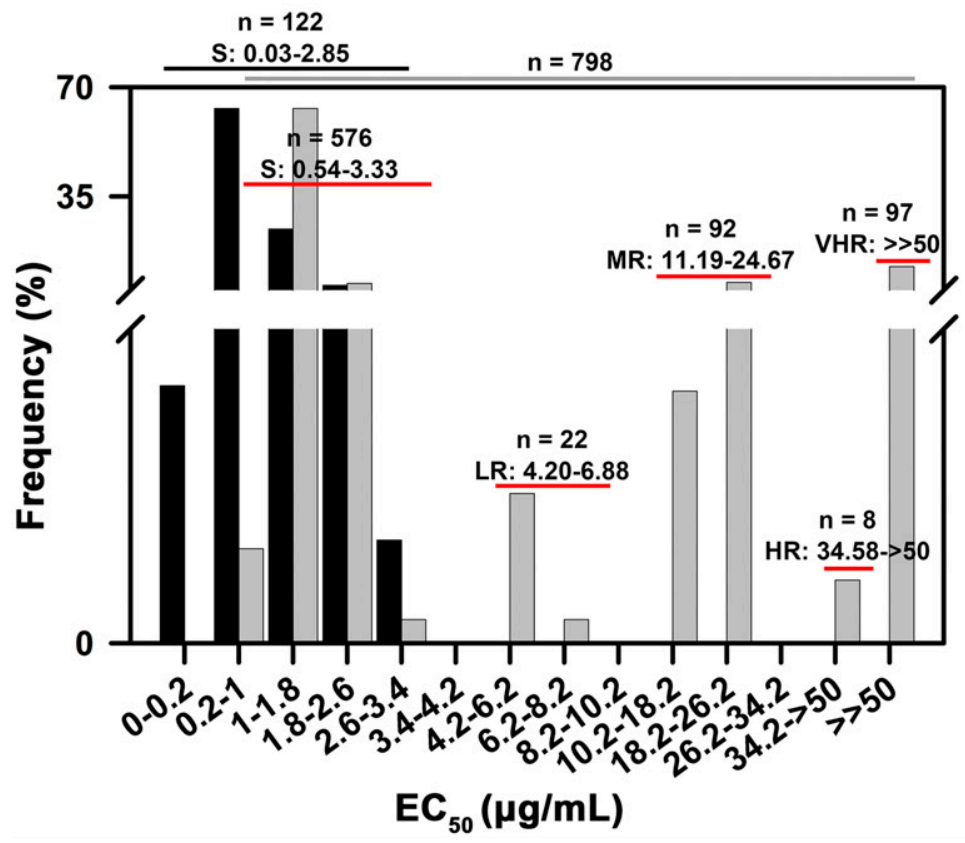

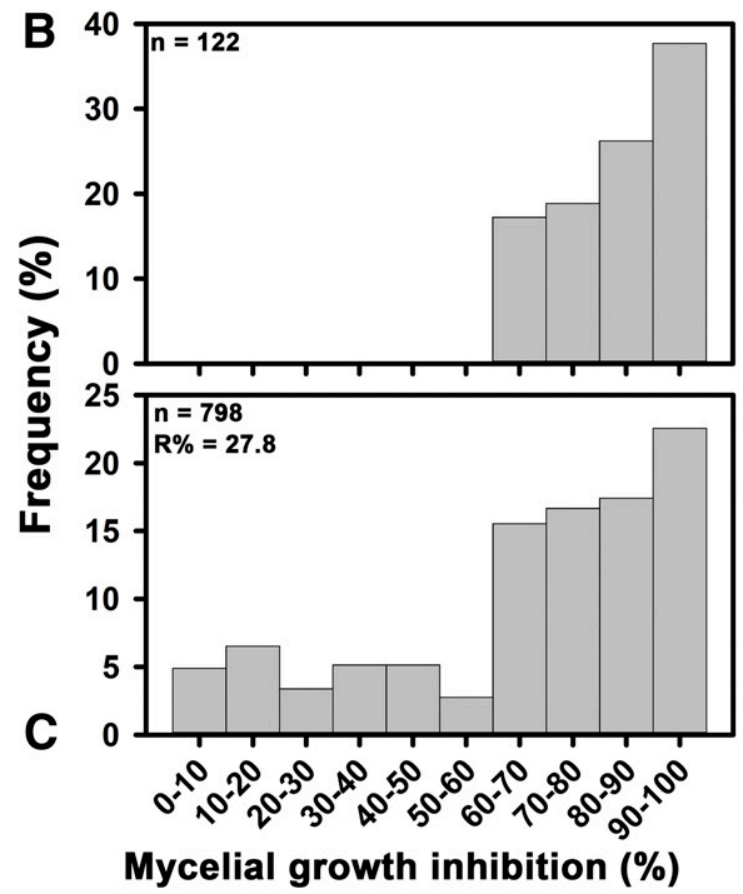

Fig. 3. Frequency distribution of $50 \%$ effective concentration $\left(E_{50}\right)$ and mycelial growth inhibition at discriminatory dose of boscalid of 122 Corynespora cassiicola isolates used for baseline establishment and 798 isolates monitored. A, Frequency distribution of $\mathrm{EC}_{50}$ values of boscalid (technical grade, $97 \%$ a.i.) for radial growth inhibition against 122 isolates of C. cassiicola isolated from cucumber (52 isolates), tomato (three isolates), eggplant (14 isolates), cowpea (12 isolates), balsam pear (seven isolates), bird-of-paradise flower (one isolate), gynura (three isolates), Hevea brasiliensis (10 isolates), hot pepper (two isolates), kidney bean (11 isolates), lettuce (three isolates), poinsettia (two isolates), ramie (one isolate), and scarlet sage (one isolate) with no history of boscalid usage (black bars), and 798 isolates collected from greenhouses or fields with or without a history of boscalid treatment (gray bars), on PDA agar medium after a 5 -day incubation at $26^{\circ} \mathrm{C}$ in darkness. Break position was at $50 \%$ of the Y-axis, omit from 5 to $5 \%$, post break interval was $35 \%$. B and C, Distribution of mycelial growth inhibition at discriminatory dose of boscalid (Cantus 50 WG, BASF): the mycelial growth inhibition of the 122 isolates was higher than $60 \%$ (B), and two peaks at $15 \%$ and $35 \%$, corresponding to the very highly resistant population and the moderately resistant population, were obvious in the mycelial growth inhibition distribution of the 798 isolates (C). 
detected in 10 isolates with low resistance to boscalid. One isolate moderately resistant to boscalid carried the substitution from aspartic acid to glutamic acid in SdhD (SdhD-D95E, GAC $\rightarrow$ GAA), one isolate highly resistant to boscalid possessed one substitution of a histidine by a arginine at amino acid position 105 in SdhD (SdhD-H105R, $\mathrm{CAC} \rightarrow \mathrm{CGC}$ ), and one isolate highly resistant to boscalid carried substitution of a glycine by a valine at amino acid position 109 in SdhD (SdhD-G109V).

\section{Discussion}

Development of a new fungicide for crop protection is timeconsuming and expensive, so it is important to take full advantage of fungicides that are currently available on the market. In Japan, boscalid has been marketed for the management of Corynespora blight since 2006, suggesting that it could be used to protect cucumber against $C$. cassiicola infection in China. However, a nontarget pathogen in Japanese cucumber greenhouses, namely the powdery mildew fungus $P$. xanthii, has developed resistance to boscalid after 2 to 3 years of application to control Corynespora blight (Ishii et al. 2011; Miyamoto et al. 2009); correspondingly, C. cassiicola, also a nontarget pathogen, had been under the pressure of boscalid for many

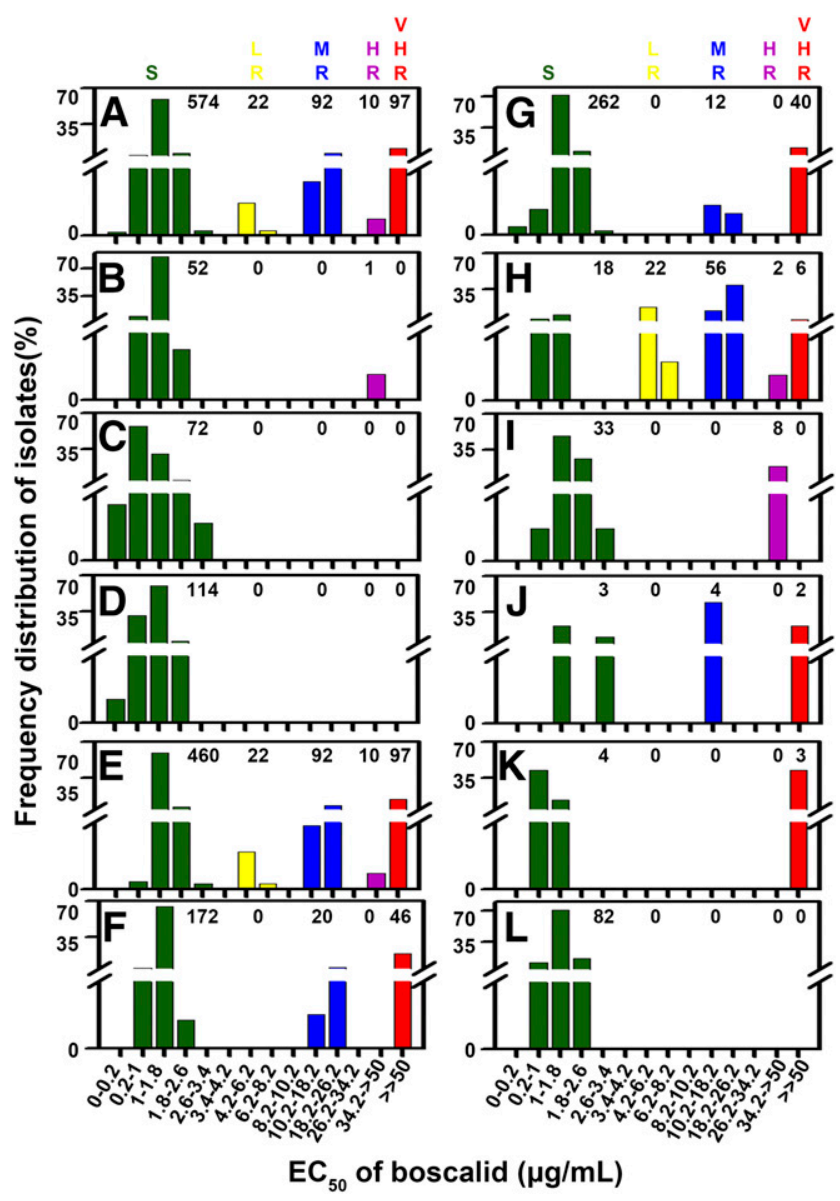

Fig. 4. Frequency distribution of Chinese Corynespora cassiicola according to the $\mathrm{EC}_{50}$ values determined on PDA plates supplemented with boscalid (technical grade, $97 \%$ a.i.). A, Frequency distribution of 795 isolates collected from cucumber. B, Frequency distribution of 53 isolates collected from tomato. C, Frequency distribution of 72 isolates collected from other hosts. D, Frequency distribution of 114 isolates collected from cucumber before 2014. E, Frequency distribution of 681 isolates from cucumber collected after 2014. F, Frequency distribution of 238 isolates from cucumber in Shandong Province. G, Frequency distribution of 314 isolates from cucumber in Hebei Province. H, Frequency distribution of 104 isolates from cucumber in Liaoning Province. I, Frequency distribution of 41 isolates from cucumber in Beijing city. J, Frequency distribution of nine isolates from cucumber in Tianjin city. K, Frequency distribution of seven isolates from cucumber in Henan Province. L, Frequency distribution of 82 isolates from cucumber in other administrative areas. Break position was at $5 \%$ of $Y$-axis, omit from 5 to $5 \%$, post break interval was $35 \%$. years, since boscalid has been used to control cucumber gray mold in Chinese cucumber greenhouses since 2008 (China Pesticide Information Network 2016). Thus, monitoring the sensitivity of $C$. cassiicola to boscalid is crucial for disease management in the field.

Resistance has been observed primarily in C. cassiicola populations collected from cucumber since 2014 in our study (Fig. 4), mainly distributed in Liaoning Province, Hebei Province, Beijing, Tianjin, Shandong Province, and Henan Province. Isolates collected before 2014 from other hosts or from other provinces or municipalities were sensitive to boscalid, with an exception of one resistant isolate from tomato in Zhejiang Province. Thirty-one isolates from tomato collected in Hubei Province after 2014 were sensitive, which was reasonable because the registered target fungus $B$. cinerea from tomato greenhouses was recently demonstrated to be sensitive in Hubei Province in China (Fan et al. 2016). However, no resistant isolates from cucumber were found in other provinces and municipalities, although the number of available isolates is small, especially for Gansu Province, with only one isolate tested in this study. Thus, additional research should be conducted to further clarify the resistance level of $C$. cassiicola from other hosts and other provinces.

In general, cross-resistance is common between fungicides belonging to the same chemical class with a similar mode of action, but this is not true in all cases (Thomas et al. 2012). In the current study, cross-resistance between boscalid and penthiopyrad or carboxin, and a lack of cross-resistance between boscalid and fluopyram, were in agreement with other reports on C. cassiicola and other different fungi (Avenot et al. 2012; Ishii et al. 2011; Veloukas et al. 2013; Yin et al. 2011). Previous studies have suggested that different levels of cross-resistance between SDHIs is related to chemical structure and diverse point mutations in $s d h$ genes (Avenot et al. 2014; Scalliet et al. 2012; Veloukas et al. 2013). Currently, at least 27 mutations in SdhB/C/D subunits have been reported in 14 types of plant pathogen (FRAC), and five mutations have been reported in boscalid-resistant $C$. cassiicola, including SdhB-H278Y/R, SdhC-S73P, and SdhD-G109V/SdhD-S89P (Miyamoto et al. 2010). A study by Fernández-Ortuño have suggested that different resistance patterns were correlated with different point mutation in the $s d h B$ gene in B. cinerea (Fernández-Ortuño et al. 2017). We correlated seven resistance patterns based on $\mathrm{EC}_{50}$ mycelial growth inhibition values (Table 2), namely pattern I $\left(\right.$ Bos $^{\text {MR }}$ Fluo $^{\text {MR }}$ Pen $^{\mathrm{LR}}$

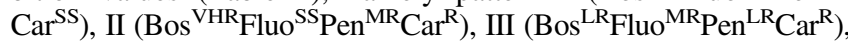
IV $\left(\right.$ Bos $^{\mathrm{MR}}$ Fluo $\left.^{\mathrm{MR}} \operatorname{Pen}^{\mathrm{MR}} \mathrm{Car}^{\mathrm{R}}\right)$, V $\left(\mathrm{Bos}^{\mathrm{HR}}{ }^{\mathrm{Fluo}}{ }^{\mathrm{MR}} \operatorname{Pen}^{\mathrm{HR}} \mathrm{Car}^{\mathrm{R}}\right)$, VI

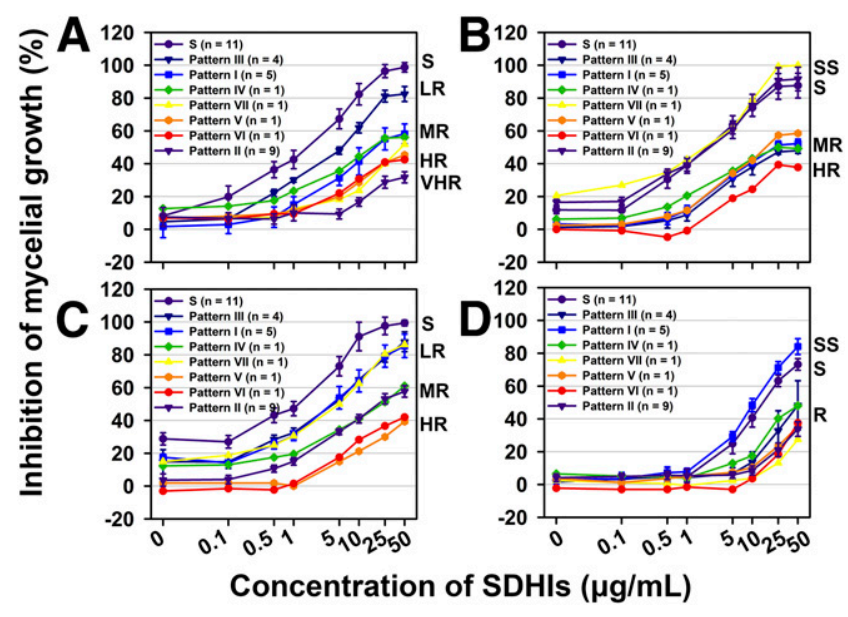

Fig. 5. Effect of concentration of technical grade boscalid (A), fluopyram (B), penthiopyrad (C), and carboxin (D) on PDA agar medium on inhibition of mycelial growth from 33 Corynespora cassiicola isolates with different resistance levels to boscalid after a 5-day incubation at $26^{\circ} \mathrm{C}$ in darkness. Based on the effect, seven resistant phenotypes were obtained, namely pattern I (Bos $\left.{ }^{M R} F_{F l u o}{ }^{M R} P_{P e n}{ }^{L R} C a r{ }^{R S}\right)$,

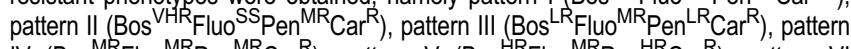
IV (Bos ${ }^{\mathrm{MR}} \mathrm{Fluo}^{\mathrm{MR}} \mathrm{Pen}^{\mathrm{MR}} \mathrm{Car}^{\mathrm{R}}$ ), pattern V (Bos $\left.{ }^{\mathrm{HR}_{\mathrm{R}}} \mathrm{Fluo}^{\mathrm{MR}} \mathrm{Pen}^{\mathrm{HR}} \mathrm{Car}^{\mathrm{R}}\right)$, pattern VI

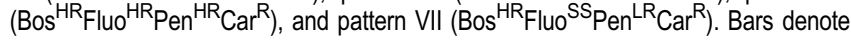
standard deviation. No bars were added for these resistant phenotypes with only one isolate. 
$\left(\right.$ Bos $\left.^{\mathrm{HR}} \mathrm{Fluo}^{\mathrm{HR}} \mathrm{Pen}^{\mathrm{HR}} \mathrm{Car}^{\mathrm{R}}\right)$, and VII $\left(\mathrm{Bos}^{\mathrm{HR}} \mathrm{Fluo}^{\mathrm{SS}} \mathrm{Pen}^{\mathrm{LR}} \mathrm{Car}^{\mathrm{R}}\right)$ to seven individual amino acid changes SdhC-S73P, SdhB-H278Y, SdhB-I280V, SdhD-D95E, SdhD-H105R, SdhD-G109V, and SdhBH278R (Table 3). Amino acid substitutions SdhB-H278Y/R did not correspond to cross-resistance between boscalid and fluopyram, while other mutations in $s d h B / C / D$ resulted in positive cross-resistance between boscalid and fluopyram (Fig. 5 and 6). The lack of crossresistance and positive cross-resistance between boscalid and fluopyram had already been confirmed in VHR/HR (SdhB-H278Y/R) and MR (SdhC-S73P, SdhD-S89P, and SdhD-G109V) isolates in C. cassiicola in mycelial growth tests on YBA and also in inoculation tests on potted cucumber plants, respectively (Ishii et al. 2011; Miyamoto et al. 2010). In this study, only one $C$. cassiicola isolate carried the SdhD-G109V alteration (resistant phenotype of VI). A different culture medium was probably the reason why a different resistance level was observed in the isolates that carried the same mutation in our research and research by Miyamoto et al. (2010). Only one $C$. cassiicola isolate carried the SdhD-H105R mutation (V). This mutant showed cross-resistance between boscalid and the other three SDHIs, but lower resistance level was observed for fluopyram, not for penthiopyrad as in homologous mutant of A. alternata (Avenot et al. 2014). The SdhD-D95E exchange (resistant phenotype of VI), carried by only one $C$. cassiicola isolate, was associated with MR to boscalid and penthiopyrad, which induced
MR to boscalid and strongest resistance to penthiopyrad in A. alternata (Yang et al. 2015). The SdhB-I280V mutation conferred low resistance level to boscalid and penthiopyrad, and moderate resistance to fluopyram in current research, which corresponds to the limited resistance factors induced by the homologous mutation of SdhB-I269V in Mycosphaerella graminicola (Scalliet et al. 2012).

Two commercially available fungicides containing fluopyram with a second active ingredient as tebuconazole or trifloxystrobin have been registered to control cucumber Corynespora blight in China since 2015. In the cross-resistance study, isolates collected from Liaoning Province that carried the mutation of SdhB-I280V seem to have developed moderate resistance to fluopyram (Table 2). If resistance had developed to one active ingredient in the mixture, especially for those with single-site modes of action, the other ingredient was subsequently applied singly, resulting in the occurrence of multiply resistant isolates (Weber 2011). Thus, the in vivo efficacy of fluopyram for these moderate isolates must be determined. We must devote greater attention to monitoring the fluopyram resistance of $C$. cassiicola and be cautious in our use of commercial agents containing fluopyram and tebuconazole or fluopyram and trifloxystrobin in Liaoning Province.

In conclusion, we characterized the frequency and distribution of boscalid resistance in $C$. cassiicola in China. Results revealed that resistance of $C$. cassiicola to boscalid in China is widespread and
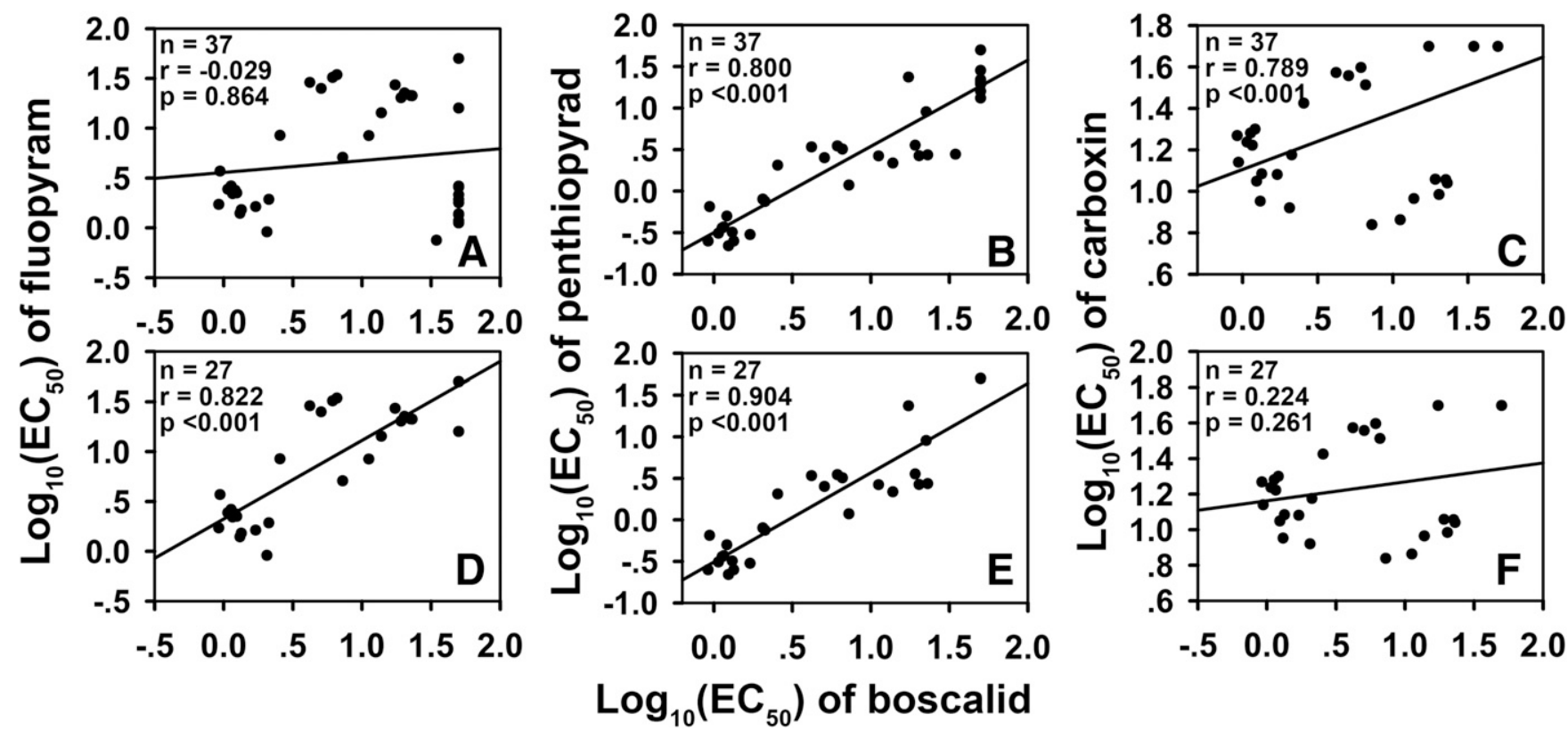

Fig. 6. Pearson correlation coefficients of the sensitivity of Corynespora cassiicola isolates to boscalid and to fluopyram (A, no significant cross-resistance between boscalid and fluopyram and $\mathbf{D}$, significant positive cross-resistance was observed between boscalid and fluopyram when omitting the nine isolates affiliated with resistance type II and one isolate of resistance type VII); penthiopyrad (B and $\mathbf{E}$, strong correlations were observed between boscalid and penthiopyrad); and carboxin (C, strong correlations were observed between boscalid and carboxin, and $\mathbf{F}$, no significant cross-resistance was observed between boscalid and fluopyram when omitting the nine isolates affiliated with resistance type II and one isolate of resistance type VII). Sensitivity to boscalid (technical grade), represented by logarithmic transformed $\mathrm{EC}_{50}$ values, is plotted against sensitivity to other three SDHI fungicides (technical grade).

Table 3. Amino acid substitutions in the SdhB/C/D subunits of seven succinate dehydrogenase inhibitor resistance patterns of Corynespora cassiicola

\begin{tabular}{|c|c|c|c|c|c|c|c|c|}
\hline \multirow[b]{3}{*}{ Pattern } & \multirow[b]{3}{*}{$\mathbf{N}^{\mathbf{a}}$} & \multicolumn{7}{|c|}{ Genotype } \\
\hline & & \multicolumn{3}{|c|}{ SdhB } & \multirow{2}{*}{$\frac{\text { SdhC }}{\text { S73P }}$} & \multicolumn{3}{|c|}{ SdhD } \\
\hline & & H278Y & H278R & $\overline{\mathrm{I} 280 \mathrm{~V}}$ & & $\overline{\mathrm{D} 95 E}$ & H105R & G109V \\
\hline I Bos ${ }^{\mathrm{MR}}$ Fluo $^{\mathrm{MR}} \mathrm{Pen}^{\mathrm{LR}} \mathrm{Car}^{\mathrm{SS}}$ & 7 & 0 & 0 & 0 & 7 & 0 & 0 & 0 \\
\hline II Bos ${ }^{\mathrm{VHR}}$ Fluo $^{\mathrm{SS}} \mathrm{Pen}^{\mathrm{MR}} \mathrm{Car}^{\mathrm{R}}$ & 9 & 9 & 0 & 0 & 0 & 0 & 0 & 0 \\
\hline III Bos ${ }^{\mathrm{LR}} \mathrm{Fluo}^{\mathrm{MR}} \mathrm{Pen}^{\mathrm{LR}} \mathrm{Car}^{\mathrm{R}}$ & 5 & 0 & 0 & 5 & 0 & 0 & 0 & 0 \\
\hline IV Bos ${ }^{\mathrm{MR}}$ Fluo $^{\mathrm{MR}} \mathrm{Pen}^{\mathrm{MR}} \mathrm{Car}^{\mathrm{R}}$ & 1 & 0 & 0 & 0 & 0 & 1 & 0 & 0 \\
\hline V Bos ${ }^{\mathrm{HR}}$ Fluo $^{\mathrm{MR}} \mathrm{Pen}^{\mathrm{HR}} \mathrm{Car}^{\mathrm{R}}$ & 1 & 0 & 0 & 0 & 0 & 0 & 1 & 0 \\
\hline VI Bos ${ }^{\mathrm{HR}}$ Fluo $^{\mathrm{HR}} \mathrm{Pen}^{\mathrm{HR}} \mathrm{Car}^{\mathrm{R}}$ & 1 & 0 & 0 & 0 & 0 & 0 & 0 & 1 \\
\hline VII Bos ${ }^{\mathrm{HR}} \mathrm{Fluo}^{\mathrm{SS}} \mathrm{Pen}^{\mathrm{LR}} \mathrm{Car}^{\mathrm{R}}$ & 1 & 0 & 1 & 0 & 0 & 0 & 0 & 0 \\
\hline
\end{tabular}

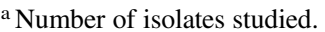


diversified. When considering the occurrence of boscalid resistance in $C$. cassiicola in the primary cucumber cultivation area in China and the cross-resistance observed in this study, we suggest that SDHIs should be banned for several years in such regions as Tianjin, Beijing, and the provinces of Liaoning, Hebei, Shandong, and Henan, where resistance existed. Also, SDHI alteration must be banned strictly to avoid the emergence of multiresistance to SDHIs, and further monitoring work in other provinces with more isolates should be performed in the future.

\section{Literature Cited}

Amiri, A., Heath, S. M., and Peres, N. A. 2014. Resistance to fluopyram, fluxapyroxad, and penthiopyrad in Botrytis cinerea from strawberry. Plant Dis. 98:532-539.

Avenot, H. F., Beggelaar, H. V. D., Morgan, D. P., Moral, J., Joosten, M., and Michailides, T. J. 2014. Sensitivities of baseline isolates and boscalidresistant mutants of Alternaria alternata from pistachio to fluopyram, penthiopyrad, and fluxapyroxad. Plant Dis. 98:197-205.

Avenot, H. F., Thomas, A., Gitaitis, R. D., Langston, D. B., Jr., and Stevenson, K. L. 2012. Molecular characterization of boscalid- and penthiopyrad-resistant isolates of Didymella bryoniae and assessment of their sensitivity to fluopyram. Pest Manag. Sci. 68:645-651.

Cha, X. F., Zhu, M. M., Wang, G. Z., and Zhang, H. P. 2009. First report of Corynespora blight in Ningxia province. Ningxia J. Agric. For. Sci. Technol. 2:40 (in Chinese).

China Pesticide Information Network. 2017. Institute Control of Agrochemicals, Ministry of Agriculture, P. R. China. http://www.chinapesticide.org.cn/ywb/ index.jhtml.

Date, H., Kataoka, E., Tanina, K., Sasaki, S., Inoue, K., Nasu, H., and Kasuyama, S. 2004. Sensitivity of Corynespora cassiicola, causal agent of Corynespora leaf spot of cucumber, to thiophanate-methyl, diethofencarb and azoxystrobin. Jpn. J. Phytopathol. 70:10-13.

Dixon, L. J., Schlub, R. L., Pernezny, K., and Datnoff, L. E. 2009. Host specialization and phylogenetic diversity of Corynespora cassiicola. Phytopathology 99:1015-1027.

Fan, F., Li, N., Li, G. Q., and Luo, C. X. 2016. Occurrence of fungicide resistance in Botrytis cinerea from greenhouse tomato in Hubei Province, China. Plant Dis. 100:2414-2421.

Fang, D. C., and Fu, J. F. 1994. First report of investigation of occurrence and morphological identification of pathogen for Corynespora blight. Plant Prot. 203(3):23-24 (in Chinese).

Fernández-Ortuño, D., Pérez-García, A., Chamorro, M., de la Peña, E., de Vicente, A., and Torés, J. A. 2017. Resistance to the SDHI fungicides boscalid, fluopyram, fluxapyroxad, and penthiopyrad in Botrytis cinerea from commercial strawberry fields in Spain. Plant Dis. 101:1306-1313.

FRAC. 2017. Pathogen risk list 2014. Fungicide Resistance Action Committee. http://www.frac.info/docs/default-source/publications/pathogen-risk/pathogenrisk-list.pdf?sfvrsn=669d419a_8.

Gu, S., Gao, X. A., Yang, H. P., Li, X. H., and Wang, Z. F. 2016. Characteristics and control techniques of Corynespora blight on vegetables in greenhouses in Huangshi city. China Vegetables 3:80-81.

Gussow, H. T. 1906. Uber eine neue krankheit an gurken in England (Corynespora mazei, gen. et spec, non). Ztschsb Pflanzenkr. 16:10-13.

Hasama, W. 1991. Occurrence and characteristics of resistant isolates of Corynespora melonis against benzimidazole compounds. Jpn. J. Phytopathol. 57:312-318.

Huang, D. Y. 2012. Tolerance and resistance mechanism of several main pathogenic fungi of vegetable base on tubulin. Ph.D. thesis. Shenyang Agricultural University (in Chinese)

Ishii, H., Miyamoto, T., Ushio, S., and Kakishima, M. 2011. Lack of crossresistance to a novel succinate dehydrogenase inhibitor, fluopyram, in highly boscalid-resistant isolates of Corynespora cassiicola and Podosphaera xanthii. Pest Manag. Sci. 67:474-482.

Ji, M. S., Long, Y. Y., and Qi, Z. Q. 2010. Sensitivity detection of Corynespora cassiicola to prochloraz in Liaoning province. Jiangsu Agric. Sci. 2:127-128 (in Chinese).

Kim, Y. K., and Xiao, C. L. 2010. Resistance to pyraclostrobin and boscalid in populations of Botrytis cinerea from stored apples in Washington State. Plant Dis. 94:604-612.

Li, B. J., Chuan, J. X., Yang, M., and Du, G. F. 2014. First report of Corynespora leaf spot caused by Corynespora cassiicola on Gynura in China. Plant Dis. 98:1007.

Li, B. J., Zhao, Y. J., Yu, S. J, Chai, A. L., and Gao, W. 2008. Plant disease identification notes by Baoju Li (sixth): Outbreak of Corynespora blight in Qin county, Hebei province in the autumn of 2008. China Vegetables 11: 51-52 (in Chinese).
Li, C. S., Zhang, M., Li, L., Li, F., Qi, J. S., Xu, Z. T., and Zhang, B. 2009 Identification of cucumber target leaf spot (brown spot) pathogen and its control. China Vegetables 18:29-33 (in Chinese with English abstract).

Liu, M. T., Xu, R. F., Jiang, X. J., and Cheng, X. Y. 2003. Preliminary study on leaf spot caused by Corynespora cassiicola on cucumber. Henan Agric. Sci. 8:33-35 (in Chinese).

McKay, A. H., Hagerty, G. C., Follas, G. B., Moore, M. S., Christie, M. S., and Beresford, R. M. 2011. Succinate dehydrogenase inhibitor(SDHI) fungicide resistance prevention strategy. N. Z. Plant Prot. 64:119-124.

Miyamoto, T., Ishii, H., Seko, T., Kobori, S., and Tomita, Y. 2009. Occurrence of Corynespora cassiicola isolates resistant to boscalid on cucumber in Ibaraki Prefecture, Japan. Plant Pathol. 58:1144-1151.

Miyamoto, T., Ishii, H., Stammler, G., Koch, A., Ogawara, T., Tomita, Y., Fountaine, J. M., Ushio, S., Seko, T., and Kobori, S. 2010. Distribution and molecular characterization of Corynespora cassiicola isolates resistant to boscalid. Plant Pathol. 59:873-881.

Pernezny, K., Stoffella, P., Collins, J., Carroll, A., and Beaney, A. 2003. Control of target spot of tomato with fungicides, systemic acquired resistance activators, and a biocontrol agent. Plant Prot. Sci. 38:81-88.

Qi, P. K., Bai, J. K., and Zhu, G. X. 1960. Pages 479-480 in: Flora fungorum sinicorum on cultivated plant in Jilin province. Science Press, Beijing (in Chinese).

Qi, Z. Q., Ji, M. S., Lu, T., Wang, Y. Z., Li, X. H., and Wei, S. H. 2009. In vitro screening of effective fungicides against Corynespora cassiicola. Plant Prot. 35:140-143 (in Chinese with English abstract).

Ruprecht, J., Yankovskaya, V., Maklashina, E., Iwata, S., and Cecchini, G. 2009 Structure of Escherichia coli succinate: quinone oxidoreductase with an occupied and empty quinone-binding site. J. Biol. Chem. 284:2983629846.

Scalliet, G., Bowler, J., Luksch, T., Kirchhofer-Allan, L., Steinhauer, D., Ward, K. Niklaus, M., Verras, A., Csukai, M., Daina, A., and Fonne-Pfister, R. 2012. Mutagenesis and functional studies with succinate dehydrogenase inhibitors in the wheat pathogen Mycosphaerella graminicola. PLoS One 7: e35429.

Schlub, R. L., Smith, L. J., Datnoff, L. E., and Pernezny, K. 2009. An overview of target spot of tomato caused by Corynespora cassiicola. Acta Hortic. 808: 25-28.

Tang, P., Li, Z. Z., Peng, D. Y., Cui, H. W., Gang, S. Y., Zhou, S. Y. and Liu, L. N. 2008. Efficacy of $25 \%$ azoxystrobin suspension on Corynespora blight in cucumber. Liaoning Agric. Sci. 3:69-70 (in Chinese).

Teramoto, A., Martins, M. C., Ferreira, L. C., and Cunha, M. G. 2011. Reaction of hybrids, inhibition in vitro and target spot control in cucumber. Hortic. Bras. 29: 342-348.

Thomas, A., Langston, D. B., Jr., and Stevenson, K. L. 2012. Baseline sensitivity and cross-resistance to succinate-dehydrogenase-inhibiting and demethylationinhibiting fungicides in Didymella bryoniae. Plant Dis. 96:979-984.

Veloukas, T., Markoglou, A. N., and Karaoglanidis, G. S. 2013. Differential effect of $S d h B$ gene mutations on the sensitivity to SDHI fungicides in Botrytis cinerea. Plant Dis. 97:118-122.

Wang, Y. Y., Chai, A. L., Sun, Y., Li, B. J. 2016. Plant disease identification notes by Baoju Li (Ninety-second): Diagnosis and control advices for 6 kinds of diseases on cucumber leaves in Tianjin city and Hebei provinces. China Vegetables 3:78-80 (in Chinese).

Weber, R. W. S. 2011. Resistance of Botrytis cinerea to multiple fungicides in Northern German small-fruit production. Plant Dis. 95:1263-1269.

Xu, Y., Zhang, Z. J., Zou, Q. D., Wang, L., and Fang, D. C. 2000. Study on fungicides controlling Corynespora blight on cucumber. Liaoning Agric. Sci. 6:47-48 (in Chinese).

Yang, J. H., Brannen, P. M., and Schnabel, G. 2015. Resistance in Alternaria alternata to SDHI fungicides causes rare disease outbreak in peach orchards. Plant Dis. 99:65-70.

Yin, Y. N., Kim, Y. K., and Xiao, C. L. 2011. Molecular characterization of boscalid resistance in field isolates of Botrytis cinerea from apple. Phytopathology 101: 986-995.

Yue, H. Z. 2010. Identification and control of Corynespora blight on cucumber. Gansu Agric. Sci. Technol. 2:50-51 (in Chinese).

Zeng, R., Song, R. H., Lu, J. P., and Dai, F. M. 2011. Identification of Corynespora cassiicola infecting cucumber. In: Proceedings of the Annual Meeting of Chinese Society for Plant Pathology (in Chinese).

Zhang, Y. J., Liu, D., Ma, B. Z., Zhou, X. Y., and Miao, D. 2014. Occurrence and identification of cucumber target spot in Heilongjiang province. J. Northeast Agric. Univ. 45:34-39 (in Chinese with English abstract).

Zhang, Z. X., Li, P. L., Wang, Y. Y., Fu, J. F., Li, B. J. 2015. Plant disease identification notes by Baoju Li (Eighty-seventh): Diagnosis and control of stem rot on cucumber caused by Corynespora cassiicola. China Vegetables 10:82-84 (in Chinese). 